\title{
Bilateral Central Scotoma Due to CSCR in an Asthmatic Policeman
}

\author{
Lai Chan Fhun"1,2,3, Evelyn Tai Li Min ${ }^{1,2,3}$, Mei Fong Chong1, Ahmad Tajudin Liza-Sharmini',2,3 \\ ${ }^{1}$ Eye Clinic, Hospital Raja Permaisuri Bainun, Ipoh, Malaysia \\ ${ }^{2}$ Department of Ophthalmology, School of Medical Sciences, Health Campus, Universiti Sains Malaysia, Kubang Kerian, Malaysia \\ ${ }^{3}$ Eye Clinic, Hospital Universiti Sains Malaysia, Kota Bharu, Malaysia \\ Email: fhunella@hotmail.com
}

How to cite this paper: Fhun, L.C., Min, E.T.L., Chong, M.F. and Liza-Sharmini, A.T. (2016) Bilateral Central Scotoma Due to CSCR in an Asthmatic Policeman. Open Journal of Ophthalmology, 6, 240-245. http://dx.doi.org/10.4236/ojoph.2016.64033

Received: October 19, 2016

Accepted: November 27, 2016

Published: November 30, 2016

Copyright $\odot 2016$ by authors and Scientific Research Publishing Inc. This work is licensed under the Creative Commons Attribution International License (CC BY 4.0).

http://creativecommons.org/licenses/by/4.0/

(c) (i) Open Access

\begin{abstract}
Central serous chorioretinopathy (CSCR) is a retinal condition characterized by fluid accumulation in the subretinal space, resulting in neurosensory detachment or pigment epithelial detachment. The risk factors associated with this condition include male gender, middle age, smoking, stress and use of corticosteroids. We report a case of CSCR in a 37-year-old policeman with hypertension and bronchial asthma. He presented with sudden onset of bilateral blurring of central vision for 1 day, worse over the left eye. There were no other significant eye complaints. He is an active smoker and has been on long-term corticosteroids for asthma. On examination, the visual acuity was $6 / 9$ bilaterally. The anterior segment of both eyes was normal. Examination of the right fundus revealed a dome-shaped swelling inferior to the fovea, while the left fundus showed circular detachment of the neurosensory retina at the macula. He was diagnosed to have bilateral central serous chorioretinopathy. He was also counseled to stop smoking. The corticosteroids were continued due to the risk of precipitating an asthma attack if they were withheld. Upon his next review two months later, his condition remained stable. CSCR is usually a self-limited condition, with good visual outcome. A thorough medical, social and drug history should be obtained, and patients advised to modify their lifestyle to eliminate or reduce risk factors such as smoking, stress and corticosteroid use.
\end{abstract}

\section{Keywords}

Central Serous Chorioretinopathy, Corticosteroids, Asthma

\section{Introduction}

Central serous chorioretinopathy (CSCR) is a retinal condition characterized by fluid accumulation in the subretinal space, resulting in neurosensory detachment or pigment 
epithelial detachment [1]. CSCR has a wide spectrum of clinical features; some patients have mild symptoms, which recover spontaneously, while others have more chronic retinal dysfunction. We present a case of CSCR in an apparently healthy young man to illustrate the importance of a thorough assessment of underlying risk factors in the management of CSCR.

\section{Case Report}

A 37-year-old Malay policeman with underlying well-controlled hypertension and bronchial asthma presented with sudden onset of bilateral blurring of central vision for 1 day, worse over the left eye. There was no metamorphopsia, floaters, flashes, eye pain, eye redness or history of ocular trauma. Patient does not wear spectacles. He is an active smoker. He has been on Symbicort Turbohaler daily for the past 5 years, and tablet Micardis $40 \mathrm{mg}$ daily. He denies intake of any other medications.

The visual acuity was $6 / 9$ bilaterally. The anterior segment of both eyes was normal. Pupils were $3 \mathrm{~mm}$ bilaterally, with no relative afferent pupillary defect. The intraocular pressure was $11 \mathrm{mmHg}$ bilaterally. Examination of the right fundus revealed a domeshaped swelling inferior to the fovea, while the left fundus showed circular detachment of the neurosensory retina at the macula. The optic disc was pink (Figure 1). Optical coherence tomography revealed right eye pigment epithelial detachment with minimal subretinal fluid at the fovea, and left eye pigment epithelial detachment with neurosensory detachment of the retina involving the fovea (Figure 2). Fundus fluorescein angiography (FFA) showed an ink-blot appearance in the left eye (Figure 3) and a hyperfluorescent spot in the right eye (Figure 4).

He was diagnosed to have bilateral central serous chorioretinopathy and counseled to stop smoking. Upon his next review two months later, his condition was stable.

\section{Discussion}

CSCR is usually a self-limited condition. The duration of retinal detachment is usually

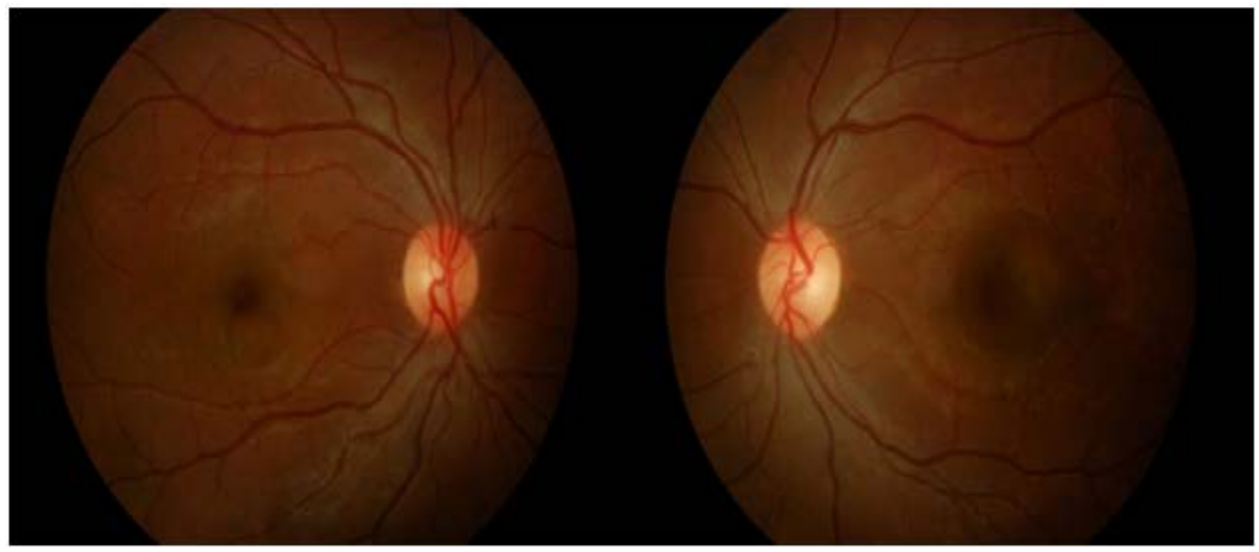

Figure 1. Fundus photos show a dome-shaped elevation inferior to the fovea in the right eye and circular detachment of the neurosensory retina at the macula with clear subretinal fluid in the left eye. 


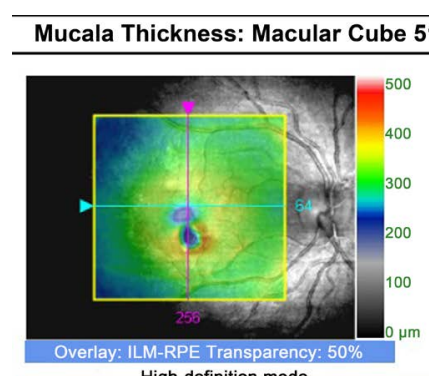

High-definition mode
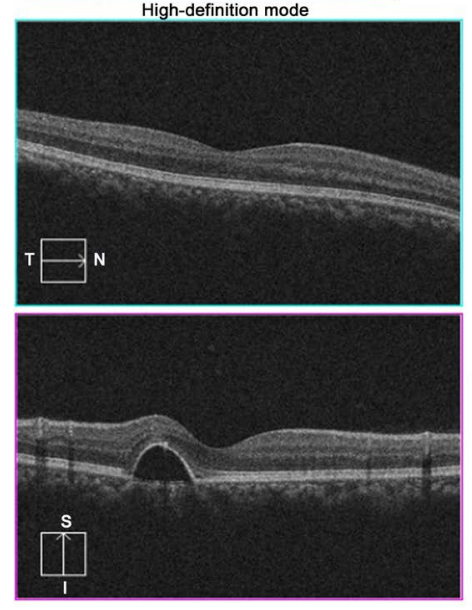

Mucala Thickness: Macular Cube $512 \times 128$

OD $\bigcirc$ OS
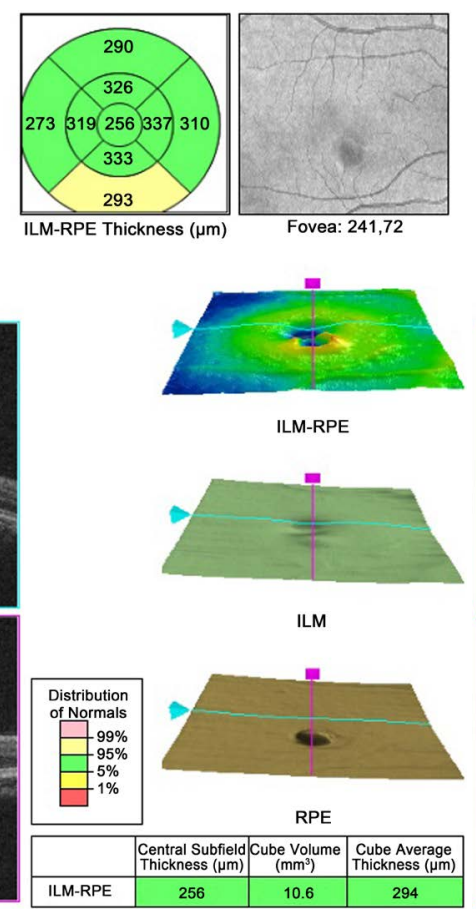

ILM-RPE
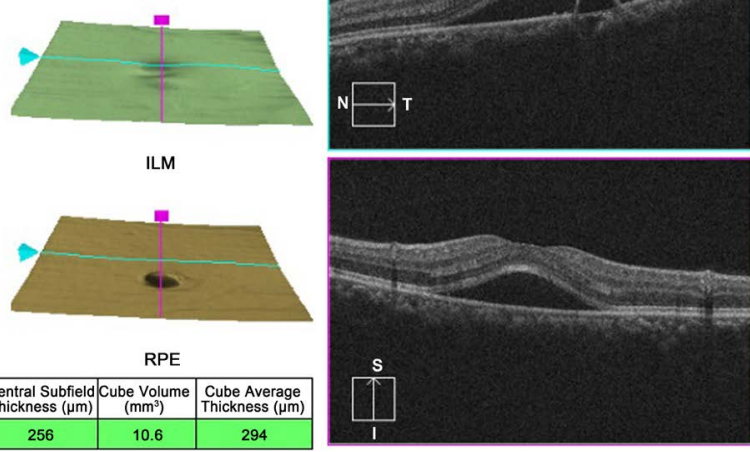
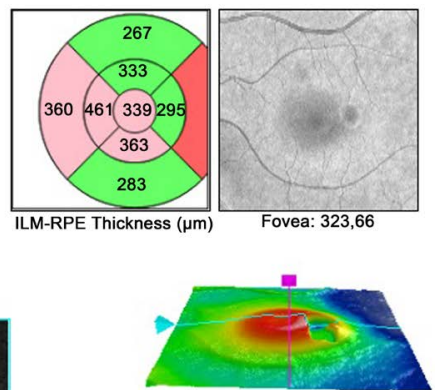

ILM-RPE

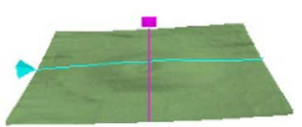

ILM

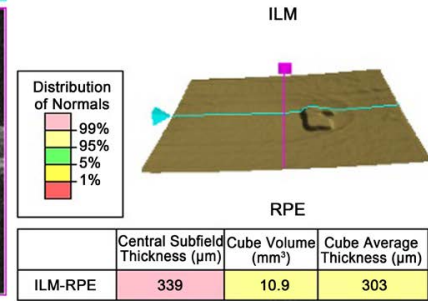

Figure 2. Optical coherence tomography showing with right eye pigment epithelial detachment with minimal subretinal fluid at the fovea and left eye pigment epithelial detachment with neurosensory detachment of the retina involving the fovea.
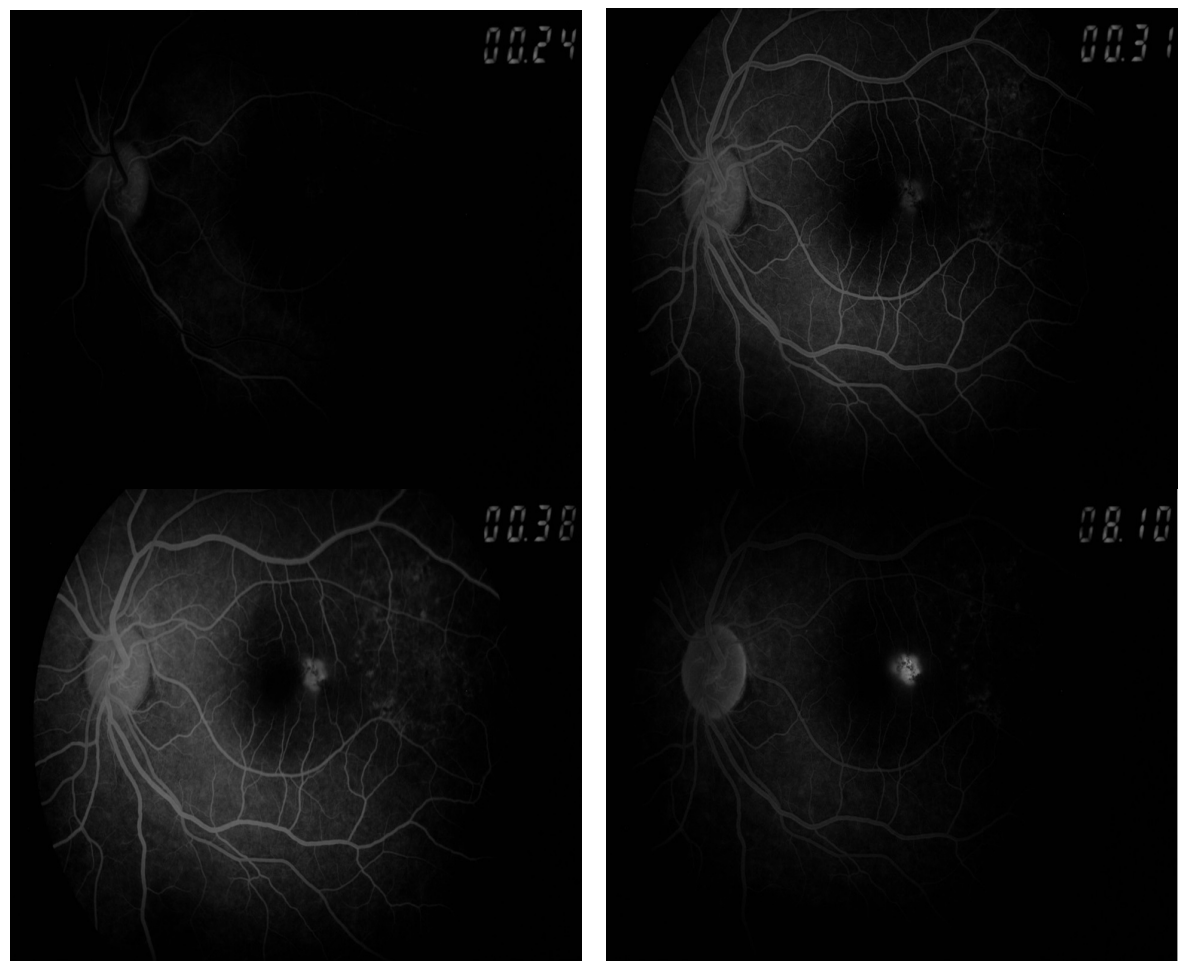

Figure 3. Fundus fluorescein angiography of the left eye showed a hyperfluorescent lesion at the macula during the arterial phase of FFA, which enlarged and increased in intensity during the later phases, suggestive of an ink blot lesion. 


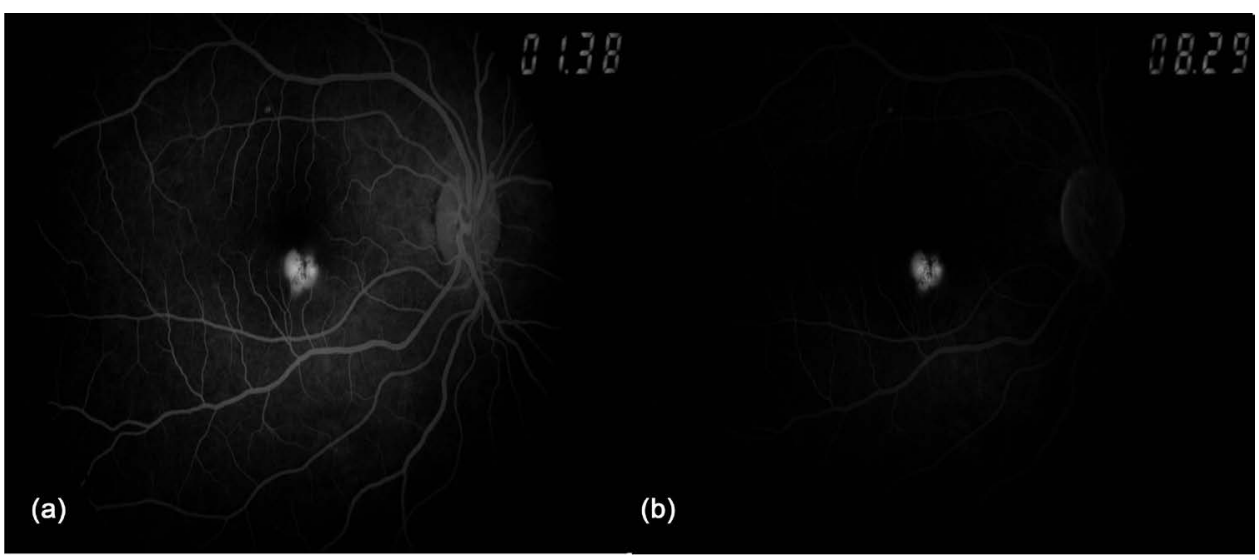

Figure 4. Fundus fluorescein angiography of the right eye revealed hyperfluorescence during the venous phase, which remained staining at late venous phase.

less than 6 months [2]. The spectrum of retinal abnormalities includes pigment migration, cystoid macular edema, and, less commonly, choroidal neovascularization (CNV) [3].

The pathogenesis of CSCR is postulated to be due to retinal pigment epithelial (RPE) dysfunction and choroidal dysfunction [4]. Another postulated mechanism is autoregulatory changes in choroidal blood flow, associated with choroiditis. This leads to mechanical disruption of the RPE barrier, damage of RPE cells and subretinal fluid accumulation [5].

The risk factors of CSCR have not been fully elucidated. Among these, type A personality and elevated endogenous cortisol are well-known associations. Gender also plays a role, with a male-to-female ratio of 8:1 among these patients. The association of CSCR with cortisol and the stress response is postulated to be due to transient hypertension and choroidal vasoconstriction, causing loss of choroidal blood flow autoregulation and RPE cell dysfunction [6] [7]. The risk factors of CSCR in this patient were male gender, age, stressful occupation, smoking and chronic use of corticosteroids.

It is important to balance the need for corticosteroids with their risks, as corticosteroid use may perpetuate CSCR. In this case, the patient's corticosteroids were continued due to the risk of precipitating an attack if they were withheld. The patient was counseled about the risk of CSCR recurrence in future, as well as advised on lifestyle modifications such as smoking cessation.

Most cases of CSCR resolve spontaneously within a few months, with a final visual acuity of $6 / 9$ or better. In our case, patient's vision on presentation remained at $6 / 9$, so we chose to monitor him while awaiting spontaneous resolution of disease.

In some patients, such as those with high visual requirements, early treatment may be considered. Likewise, in atypical cases such as bilateral or recurrent CSCR with significant effect on vision, laser may be required. Laser treatment may include options like argon laser photocoagulation or photodynamic laser therapy (PDT). Argon laser photocoagulation can speed the resolution of CSCR, but has no effect on the final visual acuity [8]. As for PDT, Maruko et al. demonstrated that PDT reduces the choroidal 
vascular permeability seen in CSCR via a different mechanism from laser treatment [9]. However, treatment with either argon laser photocoagulation or PDT may place the patient at risk of developing complications like secondary choroidal neovascular membranes [10] [11].

Another potential treatment option currently being explored is anti vascular endothelial growth factors (anti-VEGF). These agents have been postulated to hasten visual recovery [12]. However, other reports are conflicting; Unlu et al. found that intravitreal anti-VEGF injection has no significant effect on the anatomical outcome of patients with CSCR [13], while Lim et al. observed that the use of intravitreal anti-VEGF was not associated with earlier remission of disease [14]. As both PDT and anti-VEGF agents may hasten the visual recovery in CSCR, future randomized controlled trials directly comparing these two modalities will be useful.

\section{Conclusion}

CSCR is usually a self-limited condition, with good visual outcome. A thorough medical, social and drug history should be obtained, and patients advised to modify their lifestyle to eliminate or reduce risk factors such as smoking, stress and corticosteroid use.

\section{References}

[1] Ross, A., Ross, A.H. and Mohamed, Q. (2011) Review and Update of Central Serous Chorioretinopathy. Current Opinion in Ophthalmology, 22, 166-173. https:/doi.org/10.1097/ICU.0b013e3283459826

[2] Wang, M., Munch, I.C., Hasler, P.W., Prunte, C. and Larsen, M. (2008) Central Serous Chorioretinopathy. Acta Ophthalmologica, 86, 126-145.

https:/doi.org/10.1111/j.1600-0420.2007.00889.x

[3] Prakash, G., Chauhan, N., Jain, S. and Sansangi, S.K. (2013) Central Serous Chorioretinopathy: A Review of the Literature. Asia Pacific Journal of Ophthalmology, 2, 104-110. https:/doi.org/10.1097/APO.0b013e31829069ee

[4] Spitznas, M. (1986) Pathogenesis of Central Serous Retinopathy: A New Working Hypothesiois. Graefe's Archive for Clinical and Experimental Ophthalmology, 224, 321-324. https:/doi.org/10.1007/BF02150023

[5] Guyer, D.R., Yannuzzi, L.A., Slakter, J.S., Ho, A. and Orlock, D. (1994) Digital Indocyanine-Green Video Angiography of Central Serous Chorioretinopathy. Archives of Ophthalmology, 112, 1057-1062. https:/doi.org/10.1001/archopht.1994.01090200063023

[6] Haimovici, R., Rumelt, S. and Melby, J. (2003) Endocrine Abnormalities in Patients with Central Serous Chorioretinopathy. Ophthalmology, 110, 698-703. https:/doi.org/10.1016/S0161-6420(02)01975-9

[7] Bouzas, E.A., Karadimas, P. and Pournaras, C.J. (2002) Central Serous Chorioretinopathy and Glucocorticoids. Survey of Ophthalmology, 47, 5. https:/doi.org/10.1016/S0039-6257(02)00338-7

[8] Robertson, D. and Ilstrup, D. (1983) Direct, Indirect and Sham Laser Photocoagulation in the Management of Central Serous Chorioretinopathy. Taiwan Journal of Ophthalmology, 3, 67-70. https:/doi.org/10.1016/0002-9394(83)90265-9 
[9] Maruko, I., Iida, T., Sugano, Y., Ojima, A., Ogasawara, M. and Spaide, R.F. (2010) Subfoveal Choroidal Thickness after Treatment of Central Serous Chorioretinopathy. Ophthalmology, 117, 1792-1799. https:/doi.org/10.1016/j.ophtha.2010.01.023

[10] Ficker, L., Vafidis, G., White, A. and Leaver, P. (1988) Long-Term Follow-Up of a Prospective Trial of Argon Laser Photocoagulation in the Treatment of Central Serous Retinopathy. British Journal of Ophthalmology, 72, 829-834. https:/doi.org/10.1136/bjo.72.11.829

[11] Chan, W.M., Lam, D.S., Lai, T.Y., Tam, B.S., Liu, D.T. and Chan, C.K. (2003) Choroidal Vascular Remodelling in Central Serous Chorioretinopathy after Indocyanine Green Guided Photodynamic Therapy with Verteporfin: A Novel Treatment at the Primary Disease Level. British Journal of Ophthalmology, 87, 1453-1458.

https:/doi.org/10.1136/bjo.87.12.1453

[12] Lu, H.Q., Wang, E.Q., Zhang, T. and Chen, Y.X. (2016) Photodynamic Therapy and AntiVascular Endothelial Growth Factor for Acute Central Serous Chorioretinopathy: A Systematic Review and Meta-Analysis. Eye (London), 30, 15-22.

https://doi.org/10.1038/eye.2015.208

[13] Unlu, C., Erdogan, G., Aydogan, T., Sezgin Akcay, B.I., Kardes, E., Kiray, G.A. and Bozkurt, T.K. (2016) Intravitreal Bevacizumab for Treatment of Central Serous Chorioretinopathy. Journal of Ophthalmic and Vision Research, 11, 61-65. https:/doi.org/10.4103/2008-322X.180700

[14] Lim, J.W., Ryu, S.J. and Shin, M.C. (2010) The Effect of Intravitreal Bevacizumab in Patients with Acute Central Serous Chorioretinopathy. Korean Journal of Ophthalmology, 24, 155-158. https:/doi.org/10.3341/kjo.2010.24.3.155

Submit or recommend next manuscript to SCIRP and we will provide best service for you:

Accepting pre-submission inquiries through Email, Facebook, LinkedIn, Twitter, etc. A wide selection of journals (inclusive of 9 subjects, more than 200 journals)

Providing 24-hour high-quality service

User-friendly online submission system

Fair and swift peer-review system

Efficient typesetting and proofreading procedure

Display of the result of downloads and visits, as well as the number of cited articles Maximum dissemination of your research work

Submit your manuscript at: http://papersubmission.scirp.org/

Or contact ojoph@scirp.org 